\title{
Needlescopic versus laparoscopic cholecystectomy. A prospective study of 60 patients $^{1}$
}

\author{
Colecistectomia agulhascópica versus colecistectomia laparoscópica. Um estudo prospectivo \\ de 60 pacientes
}

\author{
Pedro Henrique Oliveira Cabral', Ivan Tramujas da Costa e Silva", Janaína Vieira Melo ${ }^{\mathrm{III}}$, Felicidad Santos Gimenez ${ }^{\mathrm{IV}}$, Celso \\ Rômulo Barbosa Cabral ${ }^{\mathrm{V}}$, Ana Paula Calheiros de Lima ${ }^{\mathrm{VI}}$
}

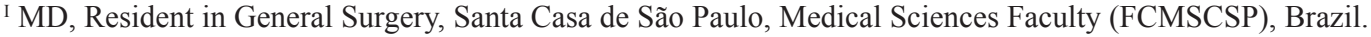 \\ II Assistant Professor, Department of Surgery, Medical College, UFAM, Manaus, Brazil.

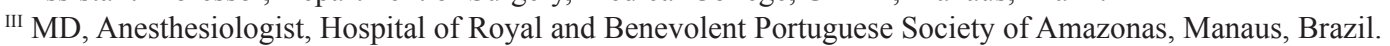 \\ Iv MD, Surgeon at University Hospital, UFAM, Manaus, Brazil. \\ v PhD, Department of Statistics, UFAM, Manaus, Brazil. \\ ${ }^{\mathrm{VI}} \mathrm{MD}$, Resident in Internal Medicine, University of Campinas (UNICAMP), Sao Paulo, Brazil.
}

\begin{abstract}
Purpose: To test the hypothesis that needlescopic cholecystectomies (NC) offer superior outcomes in comparison to common laparoscopic cholecystectomies (LC). Methods: Sixty consecutive patients with gallbladder disease undergoing either LC or NC were evaluated with respect to differences in operative time, frequency of per-operative incidents, post-operative pain, late postoperative symptoms, length of scars and level of postoperative satisfaction. Results: Mean operative time was similar in both groups. Most of the patients, irrespective of the technique, informed mild postoperative pain. NC patients had lower levels of pain on the $7^{\text {th }}$ postoperative day (PO7) $(\mathrm{p}<0.01)$ and decreased need for additional analgesia. Less frequency of epigastric wound pain was observed in NC patients until PO4 $(\mathrm{p}<0.01)$. Aesthetic result was far superior after NC (total length of scars less than half after LC). No differences regarding postoperative satisfaction with the operation were observed between the studied groups. Conclusions: Both techniques were safe and effective, presenting similar operative times and low levels of postoperative pain. Downsizing the ports to 2-3 mm was associated with significantly less frequency of postoperative pain only in the epigastric wound until PO4. Aesthetic outcome of NC was significantly superior to LC, although this advantage did not influence patient level of satisfaction
\end{abstract}

Key words: Cholecystectomy, Laparoscopic. Pain Postoperative.

\section{RESUMO}

Objetivo: Testar a hipótese de que colecistectomias agulhascópicas oferecem resultados superiores aos da colecistectomia laparoscópica usual (CL). Métodos: Sessenta pacientes consecutivos com colecistopatia submetidos à CA ou CV foram avaliados quanto ao tempo operatório, freqüência de acidentes peroperatórios, dor pós-operatória, sintomas pós-operatórios tardios, comprimento das cicatrizes e grau de satisfação. Resultados: O tempo operatório médio foi semelhante em ambos os grupos. A maioria dos pacientes, independentemente da técnica, relataram dor pós-operatória leve. Aqueles operados por CA tiveram menores níveis de dor no $7^{\circ}$ dia de pós-operatório (PO7) $(\mathrm{p}<0.01)$ e menor necessidade de analgesia adicional. Menor freqüência de dor epigástrica foi observada no grupo CA até o PO4 $(\mathrm{p}<0.01)$. O resultado estético foi amplamente superior após CA (comprimento total das cicatrizes menor que a metade após CL). Não houve diferença quanto ao grau de satisfação entre os grupos. Conclusões: As duas técnicas foram seguras e eficazes, apresentando tempos operatórios semelhantes e baixos níveis de dor pós-operatória. A redução dos portais para 2-3 mm associou-se a menor freqüência de dor pós-operatória apenas na incisão epigástrica até o PO4. O resultado estético da agulhascopia foi significantemente superior ao da laparoscopia, apesar desta vantagem não ter influenciado o grau de satisfação dos doentes.

Descritores: Colecistectomia Laparoscópica. Dor Pós-Operatória.

${ }^{1}$ Research performed at Federal University of Amazonas (UFAM) and Hospital of Royal and Benevolent Portuguese Society of Amazonas, Manaus, Brazil.

\section{Introduction}

Laparoscopic cholecystectomy (LC) was firstly considered the gold-standard operation for gallstone disease in $1992^{1}$, mainly because of the advantages brought about by the minimally invasive techniques it began to employ ${ }^{1}$. Since then, several technological developments have been achieved, some of them comprising an increasing interest towards attempting to reduce even further the surgical trauma by diminishing the caliber of the instruments. As a result of these initiatives, Gagner and Garcia-Ruiz ${ }^{2}$ introduced the term "needlescopic" for operations performed with laparoscopic instruments up to $3 \mathrm{~mm}$ in diameter, 
a definition which has been adopted by other authors ${ }^{2,3,4}$.

In recent years, an increasing number of papers have advocated this technique as feasible for a variety of abdominal procedures, including appendectomies, adrenalectomies, splenectomies, gastric fundoplications, urologic procedures and cholecystectomies ${ }^{4-7}$. There is some controversy, though, regarding the benefits of needlescopic cholecystectomy (NC), for some surgeons consider it a natural evolution of $\mathrm{LC}^{8}$, while others contend that tissue trauma in needlescopic cholecystectomy (NC) is not significantly reduced, for the $5 \mathrm{~mm}$ ports of LC are already minimal and no benefit can be achieved from further reduction. It is also argued that $\mathrm{NC}$ is more troublesome and time consuming, and that visceral pain resulting from removal of the gallbladder is similar for both procedures ${ }^{3,9,10}$.

Prospective trials comparing LC and NC have shown conflicting results, especially concerning postoperative pain. Look et al. ${ }^{11}$ randomized 64 patients and evaluated pain using a five-grade scale, concluding that there were no differences between the techniques in terms of postoperative pain, safety, operative time and functional recovery ${ }^{11}$. Other authors had similar findings ${ }^{12}$. Conversely, Cheah et al. ${ }^{13}$ assessed postoperative pain among 75 patients using a 10-grade visual pain scale and found NC was less painful, in agreement with other trials ${ }^{14-16}$.

In Brazil, Carvalho et al. ${ }^{17}$ reported the results of $719 \mathrm{NC}$ and found no differences in morbidity or mortality compared to LC. However, this was a retrospective uncontrolled series and other relevant aspects, such as postoperative pain and satisfaction, were not compared.

Due to these inconsistent results in the literature and because of the small number of regional trials on needlescopic surgery, the authors undertook this prospective controlled trial of 60 patients to evaluate if $\mathrm{NC}$ offers superior outcomes in comparison to LC.

\section{Methods}

\section{Inclusion and exclusion criteria.}

In a non-randomized, prospective, controlled trial, 60 patients from the private clinic of one of the authors (ITCS) were consecutively operated on from January 2005 to March 2006. Patients with symptomatic cholelithiasis or gallbladder polyps were included, in the absence of the following): 1) clinical, ultrasonographic or intraoperative signs of acute cholecystitis; 2) prior surgical procedures in the upper abdomen; 3) need to enlarge one of the incisions during the laparoscopic procedure; 4) Body Mass Index (BMI) $>35 \mathrm{~kg} / \mathrm{m}^{2}$; 5) contraindication to the anaesthetic protocol adopted; 6) Previous episodes of pancreatitis.

Patients were assigned either to NC or LC groups according to their intention to undergo elective needlescopic or laparoscopic cholecystectomy, after a careful explanation of the technical aspects of each one of the procedures. The above mentioned strict admittance criteria were used as an attempt to equalize baseline characteristics and make the groups comparable, for randomization was not possible due to the characteristics of the studied population (from a private surgical practice), for many patients were referred for consultation willing to be operated by the needlescopic technique.

\section{Surgery and anaesthesia}

All the operations were performed by the same surgical team according to a standardized technique described elsewhere ${ }^{18}$. Four ports were used in both groups (umbilicus, epigastrium, right hypochondrium and right flank), with the following dimensions: $12 \mathrm{~mm}, 10 \mathrm{~mm}, 5 \mathrm{~mm}$ and $5 \mathrm{~mm}$, respectively, for the LC group; and $12 \mathrm{~mm}, 2 \mathrm{~mm}, 2 \mathrm{~mm}$ and $3 \mathrm{~mm}$, respectively, for the NC group. For the needlescopic procedure, a second camera was employed with a $2 \mathrm{~mm}$ needlescope in the epigastric port for controlling the sealing of the cystic artery and cystic duct with titanium clips through the umbilical port with a $10 \mathrm{~mm}$ clip applier. The division of the ligated structures was subsequently done with single use $2 \mathrm{~mm}$ scissors in the epigastric port after reintroducing the $10 \mathrm{~mm}$ laparoscope in the umbilical port. The 10 and $12 \mathrm{~mm}$ aponeurotic wounds were closed with simple inverted "figure-of- 8 " stitches using nonabsorbable polypropylene monofilament sutures, while needlescopic incisions were simply coapted with sterile surgical adhesive tape.

General anesthesia was also standardized: induction with usual doses of fentanyl and a hypnotic drug (either etomidate or propofol) and maintenance with isoflurane or halothane. On anaesthetic induction, cefazolin ( $2 \mathrm{~g}$ ) was infused for antimicrobial prophylaxis. All incisions were infiltrated with bupivacaine $0.25 \%$ and an antiemetic drug was administered (ondansetron, $4 \mathrm{mg}$ ) on completion of the procedure. The same dressings were applied throughout the study.

Postoperatively, all the patients were allowed to resume oral intake soon after full recovery from anesthesia, as long as no intraoperative incidents had occurred. Intravenous (IV) dipyrone (1 g q.i.d.) and tenoxicam (20 mg b.i.d.) were systematically prescribed for postoperative analgesia and meperidine was also administered according to the request of each patient. After discharge from hospital, the patients were prescribed oral tenoxicam $20 \mathrm{mg}$ b.i.d. and were allowed to take dipyrone ad libitum (up to $500 \mathrm{mg}$ q.i.d.).

\section{Assessment of variables}

Data was collected by two observers (PHOP, ACPL) throughout the study. Operative time, from the first umbilical incision up to the last skin suture needed for wound closure, and intraoperative incidents were recorded for each surgery. On the first postoperative day (PO1), the following outcomes were collected: 1) overall pain intensity and presence or absence of pain in the port sites; 2) nature of postoperative symptoms; 3) surgical wounds condition, including presence of secretion and inflammation; and 4) number of doses of meperidine required for additional analgesia.

All patients were discharged from hospital within 24 hours after surgery and were given a protocol form to be completed daily with scores of intensity of wound pain and with the number of dipyrone tablets needed for pain relief.

Each patient was interviewed daily by telephone contact until PO7, being asked about the presence or absence of pain in each individual port site. On PO8, each patient came back for consultation with the surgeon, returning the completed Protocol Form. Complete clinical evaluation was again performed. 
The overall postoperative pain intensity from $\mathrm{PO} 1$ to $\mathrm{PO} 7$ was assessed through a 6-level visual pain scale (Wong-Baker scale $)^{19}$, in which level zero means no pain and score 5 means the worst possible pain (arithmetic means for each group were calculated for comparison). The pain intensity was also categorized as mild, moderate and severe for additional analysis.

Three months after surgery, each patient was visited at home and the length of their visible scars (epigastrium, right hypochondrium and flank, excluding the umbilicus) was measured with a pachymeter. The level of satisfaction (from 0 to 10) was also evaluated for comparison.

\section{Statistical analysis and ethics}

Collected data were included in an electronic spreadsheet $\left(\right.$ Microsoft Excel ${ }^{\circledR}$ ). For categorized variables, Fisher's exact and Chi-squared tests were used. The continuous variables were compared after calculation of the arithmetic means using Student's $\mathrm{t}$ test, considering that data had a normal distribution. Results were considered statistically significant when $\mathrm{p} \leq 0.05$. This trial was submitted and approved by the Ethics Committee of the Federal University of Amazonas.

\section{Results}

Eighty-eight patients were operated on along 14 months, of which 28 were excluded and 60 were included for analysis. Acute cholecystitis (nine patients) and non-adherence to some aspect of the protocol such as hypersensitivity to a standardized drug (10 patients) were the chief reasons for exclusion. Only eight cases were excluded by the need of conversions: seven from needlescopic to common laparoscopic surgery and one requiring open surgery because of an intra-hepatic scleroatrophic gallbladder. Another patient was excluded because of previous upper abdominal operation.

Baseline characteristics were similar in both groups (Table 1). Most patients were middle-aged women.

TABLE 1 - Baseline characteristics of the 60 patients

\begin{tabular}{|c|c|c|c|}
\hline Characteristic & $N C(n=30)$ & LC $(n=30)$ & $P$ value \\
\hline Mean age & 45.17 & 49.17 & 0.30 \\
\hline Gender - n (\%) & & & 0.53 \\
\hline Male & $5(16.7)$ & $8(26.7)$ & \\
\hline Female & $25(83.3)$ & $22(73.3)$ & \\
\hline Diagnosis & & & - \\
\hline Symptomatic gallstone & 29 & 29 & \\
\hline Gallbladder polyp & 1 & 1 & \\
\hline ASA score - n (\%) & & & 0.22 \\
\hline I & $24(80)$ & $19(63.3)$ & \\
\hline II & $6(20)$ & $9(30)$ & \\
\hline III & $0(0)$ & $2(6.7)$ & \\
\hline \multicolumn{4}{|l|}{ Body Mass Index (BMI) } \\
\hline$\left(\right.$ Mean in $\left.\mathrm{kg} / \mathrm{m}^{2}\right)$ & 25.6 & 25.1 & 0.65 \\
\hline
\end{tabular}

There was no significant difference in the mean operative time between the groups: $43.6 \mathrm{~min}$ for $\mathrm{LC}$ and $44.9 \mathrm{~min}$ for $\mathrm{NC}$ $(p=0.90)$. Intraoperative incidents occurred in $25 \%$ of the patients, presenting equal distribution in the two groups (Table 2). They were not serious and all the patients received oral feeding after recovery from anesthesia and were discharged from hospital in the first postoperative day.
TABLE 2 - Intraoperative incidents among the 60 patients

\begin{tabular}{|c|c|c|c|}
\hline \multirow{2}{*}{ Intraoperative event } & \multicolumn{2}{|c|}{ Group - n (\%) } & \multirow{3}{*}{$\frac{\text { Total (n) }}{5}$} \\
\hline & NC & LC & \\
\hline $\begin{array}{l}\text { Gallbladder perforation with bile } \\
\text { leakage into peritoneal cavity }\end{array}$ & 3 & 2 & \\
\hline $\begin{array}{l}\text { Gallbladder perforation with calculi } \\
\text { spillage }\end{array}$ & 0 & 3 & 3 \\
\hline Cystic artery bleeding & 1 & 0 & 1 \\
\hline $\begin{array}{l}\text { Troublesome liver } \\
\text { (gallbladder bed) }\end{array}$ & 2 & 3 & 5 \\
\hline Other * & 1 & 1 & 2 \\
\hline Total & $7(11.6)$ & $9(15)$ & $16(26.7)$ \\
\hline
\end{tabular}

$\mathrm{NC}$ - needlescopic cholecystectomy. LC - laparoscopic cholecystectomy.

*Cystic duct clip slippage (LC); enlargement of umbilical port wound - voluminous calculus (NC) 
Most patients classified their overall postoperative pain as mild and no difference was found between $\mathrm{NC}$ and $\mathrm{LC}$ until PO5 (Table 3). However, NC patients presented a tendency of faster recovery from pain and statistical significance was observed on PO5 and PO7. In the latter, for example, more than $90 \%$ of NC patients referred no pain. When the mean pain scores (instead of categorized pain) were compared, this pattern could again be observed (Figure 1).
TABLE 3 - Categorized assessment of pain in the early postoperative period

\begin{tabular}{|c|c|c|c|}
\hline PO day & $\mathrm{NC}-\mathrm{n}(\%)$ & LC - n (\%) & P-value \\
\hline First Day & & & 0,69 \\
\hline Painless & $8(26.7)$ & $6(20)$ & \\
\hline Mild pain & $10(33.3)$ & $12(40)$ & \\
\hline Moderate pain & $11(36.7)$ & $9(30)$ & \\
\hline Severe pain & $1(3.3)$ & $3(10)$ & \\
\hline Second Day & & & 0,36 \\
\hline Painless & $11(36.7)$ & $8(26.7)$ & \\
\hline Mild pain & $10(33.3)$ & $7(23.3)$ & \\
\hline Moderate pain & $8(26.7)$ & $11(36.7)$ & \\
\hline Severe pain & $1(3.3)$ & $4(13.3)$ & \\
\hline Fourth Day & & & 0,13 \\
\hline Painless & $21(70)$ & $15(50)$ & \\
\hline Mild pain & $6(20)$ & 5 (16.7) & \\
\hline Moderate pain & $3(10)$ & 7 (23.3) & \\
\hline Severe pain & $0(0)$ & $3(10)$ & \\
\hline Fifth day & & & 0,05 \\
\hline Painless & $24(80)$ & $15(50)$ & \\
\hline Mild pain & $4(13.3)$ & $8(26.7)$ & \\
\hline Moderate pain & $2(6.7)$ & 7 (23.3) & \\
\hline Severe pain & $0(0)$ & $0(0)$ & \\
\hline Sixth Day & & & 0,06 \\
\hline Painless & 25 (83.3) & $17(56.7)$ & \\
\hline Mild pain & $5(16.7)$ & $9(30)$ & \\
\hline Moderate pain & $0(0)$ & $3(10)$ & \\
\hline Severe pain & $0(0)$ & $1(3.3)$ & \\
\hline Seventh Day & & & $<0,01$ \\
\hline Painless & 28 (93.3) & $17(56.7)$ & \\
\hline Mild pain & $2(6.7)$ & $11(36.7)$ & \\
\hline Moderate pain & $0(0)$ & $1(3.3)$ & \\
\hline Severe pain & $0(0)$ & $1(3.3)$ & \\
\hline
\end{tabular}

*The values represent the number of patients in each group.

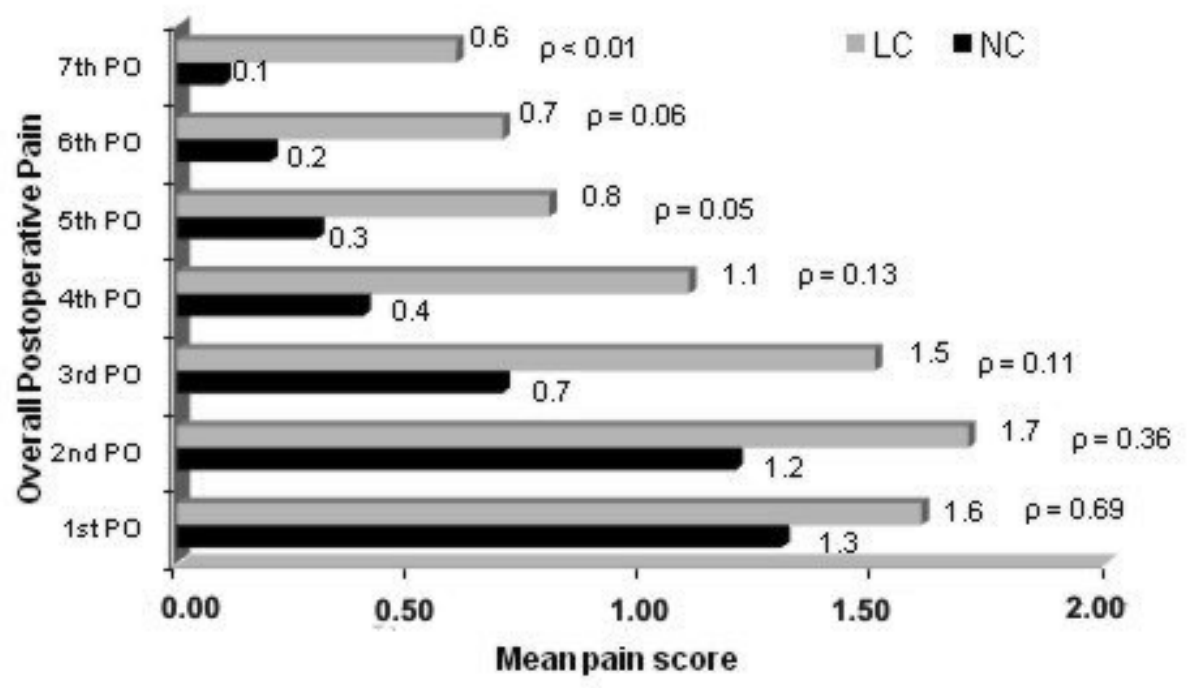

FIGURE 1 - Comparison of overall means of postoperative pain obtained through a 6-level pain scale 
Fewer patients informed pain in the epigastric port $(\mathrm{p}<0.01)$ in the NC group (Figure 2). The frequency of pain at the other port sites tended to be lower for the needlescopic technique, but no statistical difference was found (Table 4).

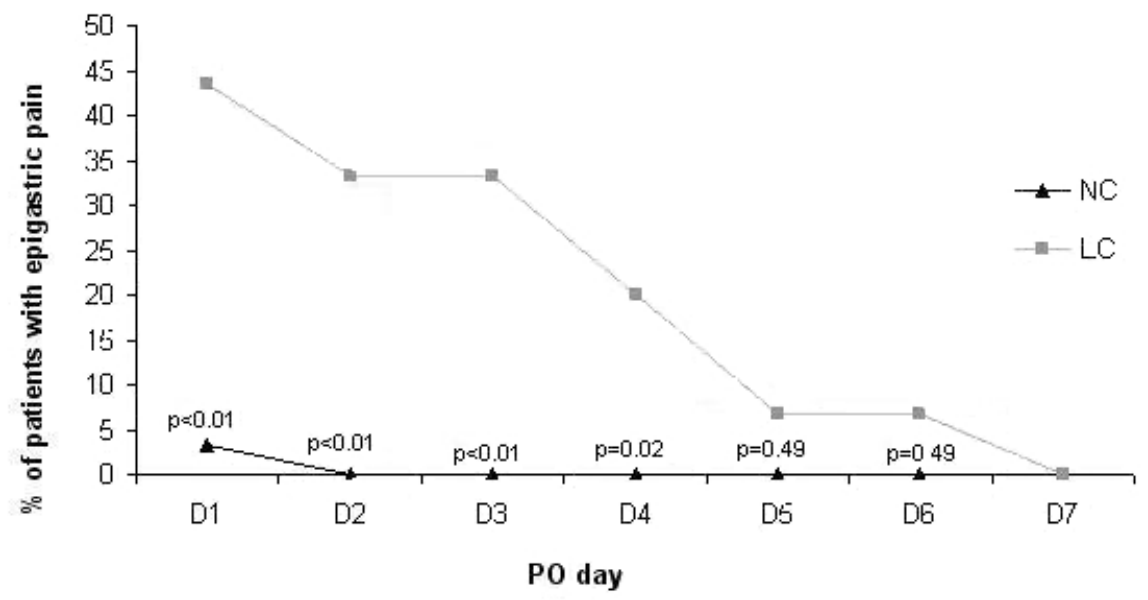

FIGURE 2 - Comparison of pain in the epigastric port between the NC and LC groups

TABLE 4 - Comparison of frequency of pain reported by the patients in each port site

\begin{tabular}{|c|c|c|c|}
\hline PO day & NC & LC & P-value \\
\hline \multicolumn{4}{|l|}{ First Day } \\
\hline Umbilicus & $9(30)$ & $14(46.7)$ & 0.23 \\
\hline Epigastrium & $1(3.3)$ & $13(43)$ & $<0.01$ \\
\hline Right hypochondrium & $5(16.7)$ & $10(33.3)$ & 0.23 \\
\hline Right flank & $3(10)$ & $2(6.7)$ & - \\
\hline \multicolumn{4}{|l|}{ Second Day } \\
\hline Umbilicus & $7(23.3)$ & $12(40)$ & 0.26 \\
\hline Epigastrium & $0(0)$ & $10(33.3)$ & $<0.01$ \\
\hline Right hypochondrium & $5(16.7)$ & $6(26.7)$ & 0.53 \\
\hline Right flank & $0(0)$ & $2(6.7)$ & 0.49 \\
\hline \multicolumn{4}{|l|}{ Third Day } \\
\hline Umbilicus & $3(10)$ & $8(26.7)$ & 0.18 \\
\hline Epigastrium & $0(0)$ & $10(33.3)$ & $<0.01$ \\
\hline Right hypochondrium & $2(6.7)$ & $6(20)$ & 0.25 \\
\hline Right flank & $0(0)$ & $1(3.3)$ & - \\
\hline \multicolumn{4}{|l|}{ Fourth Day } \\
\hline Umbilicus & $3(10)$ & $3(10)$ & - \\
\hline Epigastrium & $0(0)$ & $6(20)$ & 0.02 \\
\hline Right hypochondrium & $0(0)$ & $5(16.7)$ & 0.05 \\
\hline Right flank & $0(0)$ & $0(0)$ & - \\
\hline \multicolumn{4}{|l|}{ Fifth Day } \\
\hline Umbilicus & $1(3.3)$ & $2(6.7)$ & - \\
\hline Epigastrium & $0(0)$ & $2(6.60$ & 0.49 \\
\hline Right hypochondrium & $0(0)$ & $3(10)$ & 0.23 \\
\hline Right flank & $0(0)$ & $0(0)$ & - \\
\hline \multicolumn{4}{|l|}{ Sixth Day } \\
\hline Umbilicus & $1(3.3)$ & $3(10)$ & 0.61 \\
\hline Epigastrium & $0(0)$ & $2(6.7)$ & 0.49 \\
\hline Right hypochondrium & $0(0)$ & $3(10)$ & 0.23 \\
\hline Right flank & $0(0)$ & $0(0)$ & - \\
\hline \multicolumn{4}{|l|}{ Seventh Day } \\
\hline Umbilicus & $0(0)$ & $2(6.7)$ & 0.49 \\
\hline Epigastrium & $0(0)$ & $0(0)$ & - \\
\hline Right hypochondrium & $0(0)$ & $2(6.7)$ & 0.49 \\
\hline Right flank & $0(0)$ & $0(0)$ & - \\
\hline
\end{tabular}


There was no difference concerning requirement of additional on-demand doses of meperidine in the immediate PO period, but NC patients consumed less dipyrone tablets after discharge from hospital $(\mathrm{p}=0.05)$ (Table 5).

TABLE 5 - Comparison of on-demand dipyrone consumption for required post-operative analgesia between the two groups

\begin{tabular}{lccc}
\hline Operative & \multicolumn{3}{c}{ Number of dipyrone tablets $\mathbf{- ~} \mathbf{n}(\%)$} \\
procedure & None & $\mathbf{1}$ to $\mathbf{5}$ & $\mathbf{> 5}$ \\
\cline { 2 - 4 } NC & $21(70)$ & $8(26.7)$ & $1(3.3)$ \\
LC & $12(40)$ & $13(43.3)$ & $5(16.7)$ \\
Total & $33(55)$ & $21(35)$ & $6(10)$ \\
\hline
\end{tabular}

Regarding the esthetic result 3 months after surgery, $\mathrm{NC}$ was superior to LC as the total length of needlescopic scars was $165 \%$ shorter than LC (Table 6).

TABLE 6 - Mean length of the wound three months after surgery

\begin{tabular}{lccl}
\hline Port site & NC $(\mathbf{m m})$ & LC $(\mathbf{m m})$ & P-value \\
Epigastrium & 3.8 & 14.2 & $<0.01$ \\
Hypochondrium & 3.8 & 8.3 & 0.02 \\
Flank & 4.0 & 8.6 & $<0.01$ \\
Total length & 11.7 & 30.8 & $<0.01$ \\
\hline
\end{tabular}

During the initial three months of postoperative follow-up, late symptoms developed in 12 (20\%) patients. The most common was some degree of fatty foods intolerance (eight patients). Three patients complained of mild upper right abdominal quadrant discomfort and one patient presented exacerbation of the gastrocolic reflex. There was no instance of postcholecystectomy syndrome (Table 7).

TABLE 7 - Frequency of late postoperative ailments in the groups

\begin{tabular}{|c|c|c|}
\hline \multirow{2}{*}{$\begin{array}{l}\text { Operative } \\
\text { procedure }\end{array}$} & \multicolumn{2}{|c|}{ Late postoperative ailments $-\mathrm{n}(\%)$} \\
\hline & Present & Absent \\
\hline NC & $5(16.7)$ & $25(83.3)$ \\
\hline LC & $7(23.3)$ & $23(76.7)$ \\
\hline Total & $12(20)$ & $48(80 \%)$ \\
\hline
\end{tabular}

One late postoperative complication did occur in a patient with umbilical port wound infection and abscess formation, on PO30. This patient presented leukopenia and was subsequently diagnosed as having a myelodysplastic syndrome.

Overall, most of the patients were satisfied with the operation and no significant difference was found between the groups (Table 8).
TABLE 8 - Satisfaction with the surgery evaluated through a 10-grade analog scale

\begin{tabular}{lc} 
Operative procedure & Grade of satisfaction \\
\hline NC & 9.90 \\
LC & 9.60 \\
\hline Total & 9.75 \\
\hline
\end{tabular}

\section{Discussion}

No randomization was undertaken in this series due to the characteristics of the studied population (derived from the private practice of one of the authors - ITCS). In order to partly compensate this drawback so as to decrease its influence on the power of evidence of the compiled data, a well-known valuable tool (restriction) was used to make the groups comparable and the results as trustworthy as they could be ${ }^{20,21}$. The results were analyzed per protocol, after exclusion of 7 converted cases (NC to LC), rather than on an intention to treat basis. This design was deemed favorable because the purpose was to compare the outcome of successful NCs to successful usual LCs.

Operative time length is an important factor to be considered when comparing surgical procedures. A shorter time is theoretically beneficial for it reduces the anesthetic time, is prone to less bleeding, less third space fluid shift and, specifically in videolaparoscopic surgery, less exposure to carbon dioxide ${ }^{11,13}$.

Huang et al. ${ }^{12}$ conducted a comparative trial between NC and $\mathrm{LC}$ and stated that needlescopic procedures were about 30 minutes longer. However, that represented the initial experience of the surgeon who conducted the study. On the other hand, other authors have reported no differences in operative times regarding $\mathrm{NC}$ in comparison to $\mathrm{LC}^{11}$ demonstrating the importance of an experienced surgical team on the individual technique employed. Cheah et al. ${ }^{13}$, for example, studied 150 patients and stated that their conversion rate was lower for the last 50 patients they had operated, reflecting the experience acquired with the operations of their first 100 patients. The surgical team which undertook the present study had already performed more than 280 needlescopic procedures prior to evaluating this series of patients, and this stage of the team's learning curve certainly favored the outcomes.

Needlescopic instruments do impose some difficulties for manipulation and visualization of the surgical field, as well as for grasping fibrotic and edematous tissues ${ }^{2}$. The instruments are sharp-pointed and the $2 \mathrm{~mm}$ optic, important for visualization of cystic duct and vessels clipping during $\mathrm{NC}$, has less resolution and illumination capacity, $311,14,15$. These are aspects reported by some authors as responsible for intraoperative complications during needlescopic procedures (especially gallbladder wall and liver parenchyma perforation) as opposed to LC. However, in the present study, in analogy to others in the literature, intraoperative incidents were not more frequent during needlescopic procedures ${ }^{9}$. In this series, intraoperative incidents were all minor and could be corrected by the operative technique that was being used, contributing only to an increase in the operative time. There 
was no instance of severe complications such as biliary tract or hepatic artery injuries, associated with any of the techniques employed and there were no deaths up to three months of follow-up. Lai et al. ${ }^{13}$, in the greatest series of the literature, performed $1,011 \mathrm{NC}$ with a major complication rate of $1 \%$.

All of the patients studied herein were discharged from hospital after an overnight-stay, a practice that was proven to be safe and cost-effective ${ }^{22}$. No re-hospitalizations were needed up to 3 months of follow-up. These results emphasize that NC and LC are equally safe for patients who undergo cholecystectomy, assuming that characteristics that can render the procedures more difficult, such as cholecystitis or previous upper abdominal surgery, are absent.

These favorable results are due to the natural improvement of the technique. The visualization handicap of the $2 \mathrm{~mm}$ camera, for example, has been overcome by the use of the $10 \mathrm{~mm}$ optics up to the critical step of exposure of Calot's triangle for the appropriate dissection of the cystic duct and artery. The needlescopic optics is then employed only to monitor clip occlusion of the isolated structures ${ }^{13}$.

The multimodal analgesic therapy employed, including local anesthetic infiltration of the wounds, probably contributed to the observed low levels of postoperative pain, which are similar to other published series ${ }^{12,15,23}$. Look and colleagues found that approximately $60 \%$ of the patients they studied had mild pain or were painless, concluding that pain referral was similar after needlescopic or laparoscopic procedures ${ }^{11}$. However, they assessed pain levels only until PO3. Our study observed a significant difference in pain statement only after PO5. Although there has been at least one report showing less overall PO pain after $\mathrm{NC}^{11}$, the pattern of a more rapid pain recovery among $\mathrm{NC}$ patients is a clear finding of this study.

Pain after abdominal surgical interventions is inherently complex and multifactorial, involving visceral, wound and psychological components ${ }^{13}$. The data herein compiled show that interference in only one of these determinants (the size of the incision) did not affect substantially the overall pain intensity in most of the postoperative period.

Nonetheless, when incisional pain was analyzed separately in each port site, the epigastric port was found to have elicited less pain among NC patients. Theoretically, smaller incisions cause less tissue damage and, consequently, less pain. Therefore, the lower pain scores in the epigastric port of $\mathrm{NC}$ patients can be explained by the fact that this is the port where greater incision reduction was obtained (from $10 \mathrm{~mm}$ to $2 \mathrm{~mm}$ ). Accordingly, the umbilical port wound was reported as the most painful, probably because of its larger dimensions and also for being more manipulated during the procedures. When comparing $5 \mathrm{~mm}$ to $2-3 \mathrm{~mm}$ incisions at the other port sites, the frequency of pain did not differ significantly. In this aspect our results are comparable to those of Huang et al. ${ }^{12}$.

Of the 60 patients studied, only one (from the NC group) required additional doses of opioid (meperidine) during hospitalization. This is inconsistent with other series in which up to $50 \%$ of patients received additional on-demand analgesia ${ }^{12-14,24}$. Cheah et al. ${ }^{13}$ showed a mean of seven and 12 doses of meperidine for patients operated on by needlescopic and laparoscopic cholecystectomy, respectively, concluding that the needlescopic group required fewer intramuscular meperidine injections $(p=0.05)$.
Nevertheless, in our series, two drugs (instead of one as in the cited trials) were systematically administered as pain relievers, according to the previous experience of this group and this is a reasonable explanation for the observed differences.

Concerning the esthetic outcome, NC was shown to be superior to LC, a reality that has already been demonstrated by others $^{11,13,16,25}$. In all these studies, the length of the wound was measured early in the postoperative period. Our study was designed to evaluate the influence of the healing process on the size of the scars, so the measurements were done 90 days after surgery. NC was far superior to LC regarding length of residual scars three months after the operation. Notwithstanding this remarkable advantage, LC patients were as satisfied with the result of the operation as the patients pertaining to the NC group, implying that esthetic satisfaction may be but one of the expectations to be fulfilled by patients submitted to cholecystectomies.

\section{Conclusions}

For patients with uncomplicated gallstone disease, in this series, NC and LC procedures had similar operative times and were equally safe and effective. Overall postoperative pain intensity was similar for both techniques, although NC proved to be superior to LC in the need for home consumption of on-demand analgesics and in evoking less pain in the epigastric port wound. Nonetheless, despite these advantages and the better cosmetic results observed for NC patients at PO90, no difference in the degree of satisfaction with the procedure was detected between $\mathrm{NC}$ and LC groups.

\section{References}

1. Gallstones and Laparoscopic Cholecystectomy, NIH Consens Statement. 1992;10(3):1-20.

2. Gagner M, Garcia-Ruiz A. Technical aspects of minimally invasive abdominal surgery performed with needlescopic instruments. Surg Laparosc Endosc. 1998;8(3):171-9.

3. Ngoi SS, Goh P, Kok K, Kum CK, Cheah WK. Needlescopic or minisite cholecystectomy. Surg Endosc. 1999;13(3):303-5.

4. Huang MT, Wei PL, Wu CC, Lai IR, Chen RJ, Lee WJ. Needlescopic, laparoscopic, and open appendectomy: a comparative study. Surg Laparosc Endosc Percutan Tech. 2001;11(5):306-12.

5. Seshadri PA, Poulin EC, Mamazza J, Schlachta CM. Needlescopic decapsulation of a splenic epithelial cyst. Can J Surg. 2000;43(4):303-5. 6. Yamamoto H, Kanehira A, Kawamura M, Okada M, Ohkita Y. Needlescopic surgery for palmar hyperhidrosis. J Thorac Cardiovasc Surg. 2000;120(2):276-9.

7. Ross J, Gill I, Soble J, Sung J, Kay R. Needlescopic orchipodopexy: the technique. J Urol. 1999;161:549-55.

8. Mamazza J, Schlachta CM, Seshadri PA, Cadeddu MO, Poulin EC. Needlescopic surgery: a logical evolution from conventional laparoscopic surgery. Surg Endosc. 2001;15(10):1208-12.

9. Costa e Silva I, Nogueira J, Souza P. Colecistectomia agulhascópica: aspectos técnicos e resultados iniciais. Acta Cir Bras. 1999;14(4):50-60.

10 . Rothschild J. What alternatives has minimally invasive surgery provided the surgeon? Arch Surg. 1998;133(11):1156-59.

11. Look M, Chew SP, Tan YCl. Post-operative pain in needlescopic versus conventional laparoscopic cholecystectomy: a prospective randomised trial. J R Coll Surg Edinb. 2001;46(3):138-42.

12. Huang MT, Wang W, Wei PL, Chen RJ, Lee WJ. Minilaparoscopic and laparoscopic cholecystectomy: a comparative study. Arch Surg. 2003;138(9):1017-23. 
13. Cheah WK, Lenzi JE, So JB, Kum CK, Goh PM. Randomized trial of needlescopic versus laparoscopic cholecystectomy. Br J Surg. 2001;88(1):45-7.

14. Lai EC, Fok M, Chan AS. Needlescopic cholecystectomy: prospective study of 150 patients. Hong Kong Med J. 2003;9(4):238-42.

15. Bisgaard T, Klarskov B, Trap R, Kehlet H, Rosenberg J. Microlaparoscopic vs conventional laparoscopic cholecystectomy: a prospective randomized double-blind trial. Surg Endosc. 2002;16(3):458-64. 16. Gupta A, Shrivastava UK, Kumar P, Burman D. Minilaparoscopic versus laparoscopic cholecystectomy: a randomised controlled trial. Trop Gastroenterol. 2005;26(3):149-51.

17. Carvalho G, Silva F, Cavalcanti C. Colecistectomia minilaparoscópica sem utilização de endoclipes: técnica e resultados em 719 Casos. Rev Bras Videocir. 2007;5(1):5-11

18. Hicks CL, von Baeyer CL, Spafford PA, van Korlaar I, Goodenough B. The faces pain scale-revised: toward a common metric in pain measurement. Pain. 2001;93(2):173-83.

19. Fletcher H, Fletcher S, Wagner E. Clinical epidemiology: the essencials. 3ed. Boston: Lippincott Williams \& Wilkins; 1996.
20. Atadzhanov SK. The ways for reduction of complication rate after laparoscopic cholecystectomy at acute cholecystitis. Khirurgiia. 2007(12):26-29.

21. Deziel DJ, Millikan KW, Economou SG, Doolas A, Ko ST, Airan MC. Complications of laparoscopic cholecystectomy: a national survey of 4,292 hospitals and an analysis of 77,604 cases. Am J Surg. 1993;165(1):9-14.

22. Hollington P, Toogood GJ, Padbury RT. A prospective randomized trial of day-stay only versus overnight-stay laparoscopic cholecystectomy. Aust N Z J Surg. 1999;69(12):841-3.

23. Dubois F, Berthelot G, Levard H. Laparoscopic cholecystectomy. Technique and complications: report of 2,665 cases. Bull Acad Natl Med. 1995;179(5):1059-66.

24. Barkun JS, Barkun AN, Sampalis JS. Randomised controlled trial of laparoscopic versus mini cholecystectomy: the McGill Gallstone Treatment Group. Lancet. 1992;340(8828):1116-9.

25. Kimura T, Sakuramachi S, Yoshida M, Kobayashi T, Takeuchi Y. Laparoscopic cholecystectomy using fine-caliber instruments. Surg Endosc. 1998;12(3):283-6.

Conflict of interest: none Financial source: none

\section{Correspondence:}

Ivan Tramujas da Costa e Silva

Department of Surgery

Medical College of the Federal University of Amazonas

R. Afonso Pena, 589

69020-160 Manaus - AM Brazil

Phone: (55 92)3233-9730

Fax: (55 92)3232-3411

itramujas@ufam.edu.br

\section{How to cite this article}

Cabral PHO, Silva ITC, Melo JV, Gimenez FS, Cabral CRB, Lima APC. Needlescopic versus laparoscopic cholecystectomy. A prospective study of 60 patients. Acta Cir Bras. [serial on the Internet] 2008 Nov-Dec;23(6). Available from URL: http://www.scielo.br/acb 